\title{
Overexpression of Zinc finger (GpZF) promotes drought tolerance in grass pea (Lathyrus sativus)
}

\author{
Mitra Parsa ${ }^{{ }^{*}}$, Mona Kashanchi ${ }^{1}$, Amineh Zeinali ${ }^{1}$, Elaheh pourfakhraei $^{1}$ \\ Industrial and Environmental Biotechnology Department, Research Institute of Applied Science, ACECR, \\ Shahid Beheshti University, Tehran, Iran, Po box: 198396411
}

mona.kashanchi@yahoo.com, amineh_zeinali@yahoo.com, pourfakhraei@gmail.com Corresponding author (Email, mitraprs@gmail.com)

(7)

Date of submission: 19 October 2021

Number of tables and figures: One table, 5 figures

Word count: 2659

1

2

3

4

5

6

7

8

9

0

1

2


bioRxiv preprint doi: https://doi.org/10.1101/2021.10.19.464954; this version posted October 19, 2021. The copyright holder for this preprint (which was not certified by peer review) is the author/funder. All rights reserved. No reuse allowed without permission.

\section{Highlight:}

34

35 GpZF is a positive regulator in drought stress tolerance in grass pea.

36 


\section{ABSTRACT}

38 The genes encoding Cys2/His2-type zinc finger proteins constitute a large family in higher 39 plants consisting of a family of plant transcription factors. GpZF encodes a Cys2/His2-type zinc

40 finger protein. The purposes of this study are to elucidate further the functions of a novel zinc

41 finger transcription factor in the grass pea $(\mathrm{GpZF})$ gene involved in the drought stress response 42 in the grass pea (Lathyrus sativus) and to investigate its biochemical and physiological 43 parameters under stress conditions. GpZF was expressed in grass pea. Relative gene expression 44 analysis showed the GpZF gene in independent transgenic lines was more under drought mild 45 and severe treatments (50\% and 25\% field capacity-FC). Furthermore, overexpression of this 46 gene in grass pea results in more relative water content, free proline, and soluble sugars than the 47 wild-type (WT) plants under $50 \%$ and $25 \%$ FC stresses.

48 Moreover, in 25\% FC, the independent transgenic lines revealed an increase in survival rates and 49 dry weight than the WT plants. GpZF thus implies the positive role in drought stress tolerance in 50 Lathyrus sativus. In conclusion, the transgenic grass pea plants generated in this study could be 51 used to farm arid areas.

54 Keywords: Lathyrus sativus; GpZF gene; Zinc finger protein; Drought treatment; free proline; 55 soluble sugars; relative gene expression 
bioRxiv preprint doi: https://doi.org/10.1101/2021.10.19.464954; this version posted October 19, 2021. The copyright holder for this preprint (which was not certified by peer review) is the author/funder. All rights reserved. No reuse allowed without permission.

\section{Abbreviations:}

58

59 GpZF, grass pea Zinc Finger; FC, Field capacity; TF, transcription factor; qPCR, quantitative

60 real-time polymerase chain reaction; WT, wild-type ; RWC, relative water content 


\section{1- Introduction}

Environmental stresses, such as drought, high salinity, and low temperature, alter plant water status and severely limit plant growth and productivity primarily thanks to the photosynthetic shortage, osmotic stress restraints on plant processes, and nutrient availability interference (Chen et al., 2010; Dixit et al. , 2016; Hu et al., 2009; Ni et al., 2009; Varshney et al., 2009). Adaptation to these stresses in plants occurs at molecular, cellular, physiological, and biochemical levels.

At the molecular level, transcription factors (TFs), as regulatory genes play critical roles in responding to abiotic stresses (Wang et al. , 2014). One of the most prominent transcription factor gene families is the Zinc-finger (ZF) family (Hall, 2005). This group of TFs participate in many metabolic pathways, various biological functions, such as plant growth and development (Chrispeels et al. , 2000; Kubo et al., 1998; Sakai et al., 1995), phytohormone (Molnár et al., 2002) and biotic and abiotic stress responses (Ciftci-Yilmaz \& Mittler 2008; Lippuner et al., 1996; Mukoko Bopopi et al., 2010; Takatsuji 1998; Tian et al., 2010; van der Krol et al., 1999). The Cys2/His2-type zinc-finger is identified as DNA-binding motifs in eukaryotic transcription factors TFIIIA-type finger, which typically have a QALGGH motif within the zinc finger protein (ZFP) domain. However, it has been recognized several plants C2H2-type ZFPs without the QALGGH motif.

Grass pea (Lathyrus sativus L.) is an annual and diploid $(2 \mathrm{n}=2 \mathrm{x}=14)$ pulse crop belonging to the tribe vicieae in the family Fabaceae (Yang et al., 2014). Despite its tolerance to drought, grass pea is not affected by excessive precipitation and flooding, including poor soils and heavy clays (Almeida et al., 2015; Jiang et al., 2013; Urga et al., 2005; Yang et al., 2014). It is an excellent candidate crop for human diets and animal feeds in drought-prone areas because of promising starch and protein (Jiang et al., 2013; Yang et al., 2014). Therefore, breeding droughttolerant grass pea cultivars is imperative to adapt to environmental stresses.

It has been reported that TFs play a critical role in the regulation of many stress-responsive genes. As well, they can change the downstream regulation of gene expression and signal transduction in stress-response pathways.

ZFP36, has been shown to be induced by drought, oxidative stress, and regulated for the crosstalk between NADPH oxidase, H2O2, and MAPK in ABA signaling which lead to tolerant in rice plants (Zhang et al., 2014). ZFP185 has been displayed to be regulated plant growth and 
stress responses by affecting GA and ABA biosynthesis in rice (Zhang et al., 2016). ZAT18, a nuclear $\mathrm{C} 2 \mathrm{H} 2$ zinc finger protein, functions as a positive regulator in the plant response to drought stress in Arabidopsis (Yin et al., 2017).

They then are good candidates for the breeding stress-tolerant crop. Because zinc finger is a major transcription factor that responds to abiotic stresses (salt, dehydration, and cold), in the present study, we report on the identification of grass pea of zinc finger (GpZF), a zinc finger TF

99 in grass pea.

100

We found that the zinc finger Overexpressing showed to enhance drought resistance in

101 transgenic grass pea. Moreover, biochemical and physiological parameters relating to stress were

102 evaluated to demonstrate the function of the zinc finger.

103

\section{2- Materials and Methods}

\section{2-1- Plant material, growth conditions and stress treatments}

107

Healthy and mature seeds of grass pea (Lathyrus sativus), provided by the Research Institute of Forests and Rangeland was used as material for subsequent procedures. grown at $26 \pm 1^{\circ} \square$ under continuous light conditions for 5 to 7 days until the axillary buds are

112 prominent. The axillary meristem explants were subcultured and used for transformation 113 purposes.

114 The transgenic lines and wild-type plants were propagated from the cotyledon node. The 115 transgenic plants were taken from the tubes carefully, washed and dipped in a $0.5 \%$ thiram 116 solution and transferred to 8 -cm-diameter pots containing 2 to $4 \mathrm{~mm}$ of sand followed by $20-\mathrm{cm}$ 117 diameter pots containing the potting mixture. Plants were transferred to a greenhouse with $11824 / 18^{\circ} \square$ day/night temperatures and allowed to grow until maturity. The wild-type plants' 119 process was similar to the transgenic ones except for the $0.5 \%$ thiram solution step.

120 For drought treatment, soil-grown 12 day-old plants were subjected to progressive drought by 121 two different water treatments (50 and 25\% of field capacity - FC) was applied based on FC.

122 The FC was determined by the gravimetric method following Souza et al. (2000) methodology. 123 The drought-stressed plants compare with well-watered plants as a control. After harvesting 
124 drought-stressed and unstressed plants at the same time of the day, these samples were

125 immediately frozen in liquid nitrogen and stored at $-80^{\circ} \mathrm{C}$ before RNA isolation.

126

127

128

129

130

131

132

133

134

135

136

137

138

139

140

141

142

143

144

145

146

147

148

149

150

151

152

153

154

155

\section{2-2- Phylogenetic Analysis}

Multiple sequence alignment was performed using the National Center for Biotechnology Information (NCBI) constraint-based multiple alignment tools (https://www.ncbi.nlm.nih.gov/tools/cobalt/cobalt.cgi). A phylogenetic tree was constructed with the aligned plant $\mathrm{C} 2 \mathrm{H} 2$ zinc finger proteins using MEGA version 5.0 via the neighbour-joining method.

\section{2-3- Transgenic Plasmid Construction}

The full-length cDNA of GpZF was obtained from Lathyrus sativus using gene-specific primers: the forward primer 5'TCTAGAATGCCAACAGTGTGGTTTTC3' and reverse primer 5'TCCAGA TCATGGTTTGCAAATTACGA3'. To generate $G p Z F$-overexpressing of transgenic grass pea, the GpZF complementary DNA ( $\underline{\mathrm{cDNA}}$ ) was subcloned into the grass pea transformation vector, pBI121 under the control of the cauliflower mosaic virus (CaMV) 35S promoter. The recombinant vector was transformed into Agrobacterium strain C58. Grass pea (Lathyrus sativus) was transformed using the cotyledon node method (Wang, 2006).

\section{2-4- RNA purification and cDNA synthesis}

According to the manufacturer's protocol, total RNA from each sample was extracted using the Ribospin Plant kit (Gene All, Korea). The samples' concentration and integrity were examined by nanodrop (Thermo Fisher Scientific, 2000, USA) and 1.2\% agarose gel electrophoresis. The first-strand cDNA was synthesized based on $1 \mu \mathrm{g}$ total RNA of each sample using the M-MLV reverse transcription system (Ferementas, USA) following the method provided by the manufacturer's instructions. 


\section{2-5- Validation of candidate genes using qPCR analysis and efficiency}

Leaves of WT plants and independent transgenic lines (11, 22 and 50) exposed to drought treatments (50\% and 25\% field capacity) were used qPCR analysis. Real-time quantitative PCR was conducted with Real-time PCR System (Qiagen, Germany), using Syber Green qPCR Master Mix2x (Ampliqon, Denmark) to monitor dsDNA synthesis. An endogenous ß-tubulin was used as an internal standard for the drought stress marker gene. Primers were designed by NT Vector software (table 1). Relative expression levels were calculated using the delta threshold cycle $(\mathrm{Ct})$ methods and $2^{\square \Delta \Delta C T}$ (Livak \& Schmittgen, 2001).

\section{2-6- Measurement of free proline and total soluble sugar contents}

Free proline content of drought-treated WT and transgenic grass pea plants was measured through spectrophotometer according to the method of (Bates et al., 1973). The content of proline ( $\mu \mathrm{g} / \mathrm{g} \mathrm{FW}$ ) was quantified by the ninhydrin method. The phenol-sulfuric acid method was used to assess plants' total soluble sugar content (Dubois et al., 1956). Finally, the absorbance of proline and sugar content was determined at $520 \mathrm{~nm}$ and $485 \mathrm{~nm}$ with a spectrophotometer respectively (WPA, Sweden).

\section{2-7- Measurement of relative membrane permeability and relative water content}

Membrane permeability was measured according to (Bajji et al., 2002), with some modification. In this method, three discs in the leaf segments from seedlings were infiltrated and maintained in water for $25 \mathrm{~min}$ and $2 \mathrm{~h}$ respectively. The electrical conductivities (C1) of the obtained solutions were then determined. Next, boiling the leaf segments in deionized water was occurred for 15 min and the conductivities (C2) of the resulting solutions were measured. The relative electrolyte leakage was calculated and evaluated by the values of $\mathrm{C} 1$ to $\mathrm{C} 2(\mathrm{C} 1 / \mathrm{C} 2)$.

The fresh and dry leaves of grass pea plants were weighed. The relative water content (RWC) (Pieczynski et al., 2013) was evaluated before and after the drought treatment. 


\section{2-8- Statistical analysis}

The root length, shoot weight, and survival rate were calculated three times repeats. For relative membrane permeability, relative water content, free proline, total soluble sugars, samples were taken in three biological replicates at the indicated time after treatment. To discriminate significant differences, the data were interpreted by analysis of variance (ANOVA), and the t-test was used for determination of the least significant difference (LSD) of means.

\section{3- Results}

\section{3-1- Bioinformatic analysis of the gene GpZF}

The GpZF gene, containing a complete ORF of 1274 bp, was cloned from total RNA prepared from Lathyrus sativus seedlings using RT-PCR. This gene was homologous to C2H2-type ZFPs of Trifolium (Fig. 1A). These genes contain one Cys -x(2,4)- Cys -x(3)[LIVMFYWC]-x(8)- His -x(3,5)- His C2H2-type zinc finger, without a QALGGH motif. A phylogenetic tree was constructed by the Maximum Likelihood method with MEGA5.0 to investigate the evolutionary relationship among plant C2H2-type ZFs (Fig. 1B). The results demonstrated that GpZF was clustered with C2H2-type zinc fingers Trifolium. The upstream cis-acting regulatory element of GpZF was analyzed and found that stress- and defencerelated elements, such as W-boxes (position-134 to-139), TC-rich repeats (position-1131 to 1140), and CGTCA (position -855 to -860), were enriched in the promoter region of GpZFp, indicating that GpZF is a stress-related mRNA.

\section{3-2- Identification transgenic grass pea plants}

To elucidate the function of the GpZF in grass pea, the 35S: GpZF construct (Fig. 2A) was transformed into Lathyrus sativus via Agrobacterium. The lines of transformed explants were identified by PCR first, and 52 independent lines were PCR positive (data not shown). The percentage of PCR regenerated lines is $36.6 \%$. Semi-quantitative RT-PCR was conducted to evaluate the expression level of GpZF in these independent lines. The expression level of GpZF in three different independent transgenic lines; 11, 22 and 50 was significantly higher than that in the wild-type plants (Fig. 2B), which qRT-PCR analysis confirmed the expression level of this 
219

220

221

222

223

224

225

226

227

228

229

230

231

232

233

234

235

236

237

238

239

240

241

242

243

\section{Discussion}

245

246 Transcription factors are the important components of the complicated gene regulatory networks

247 that can regulate the expression of the amount of various stress-responsive genes to deal with 248 stress (Kiełbowicz-Matuk, 2012; Lan et al., 2017). The C2H2-type zinc finger transcription

gene in mentioned lines. These were chosen for further analysis subsequently (Fig. 2C). Being an annual legume, T0 generation of grass pea seedlings were used to verify drought tolerance of GpZF.

\section{3-3- Overexpression of GpZF on growth conditions in transgenic grass pea}

After regeneration of grass pea (Fig. 3A, B, C and D), the T0 generation of the putative transformants for the incorporated gene was tested.

Under normal growth conditions, overexpression of GpZF does not lead to any significant observable effects in plant growth habits. However, after drought treatment $(50 \%$ and $75 \%$ field capacity), leaves of wild-type plants showed severe wilting and chlorosis, whereas transgenic lines grew well with leaves slightly yellow. In drought stress, transgenic lines grew better than wild-type plants. The shoot height of transgenic lines was considerably higher than that of wildtype plants (Fig. 4A, B). Furthermore, the survival rate of transgenic lines was significantly higher than that of wild-type plants (Fig. 4C).

Under drought conditions, the relative water content and the relative membrane permeability of wild-type plants was more remarkable than those of the lines overexpressing GpZF (Fig. 5A and B).

As a result of abiotic stresses, plants can cumulate more osmolytes compatibility, such as free proline and soluble sugars as osmoprotectants (Irigoyen et al. 1992). Therefore, proline and soluble sugar contents were analyzed in transgenic and wild-type plants. There was no significant difference between wild-type and transgenic lines under the control conditions; however, after drought treatment, compared with the wild-type plants, independent transgenic lines showed markedly higher free proline and soluble sugars (Fig. 5C, D).

\footnotetext{
factors were caused to be involved in plant development and have various adaptive responses to
} 
abiotic stresses such as drought. In the present study, we characterized a new $\mathrm{C} 2 \mathrm{H} 2$ zinc finger transcription factor ZF (GpZF) from grass pea. Sequence analyses revealed that GpZF had an identity with other $\mathrm{C} 2 \mathrm{H} 2$ zinc finger proteins without QALGGH amino acid sequences. Lack of conserved QALGGH motif has been previously been shown to enhance Arabidopsis tolerance to cold stress ( Luo et al., 2014). However, studies on GsZFP1 gene transformation without the typical QALGGH motif in Arabidopsis revealed that it played an important role in withstanding cold and drought stresses ( Luo et al., 2012), suggesting that the QALGGH motif in the GsZFP1 protein was not imperative for adaptation to abiotic stress in wild soybean. In our study, GpZF also did not have a plant-specific typical QALGGH motif, meaning that this motif was not vital for plant response to abiotic stresses in grass pea.

Although decreased gas exchange results in the reduction of photosynthetic production during stomatal closure, decreased transpiration can reduce water loss from leaves (Ciftci-Yilmaz \& Mittler, 2008). Therefore, this process leads to growth inhibition. In drought conditions, ABA alteration of guard cell ion transport, increasing stomatal closure and preventing stomatal opening, which reduces water loss ( Kim et al., 2011). A sensitivity to ABA is not necessarily coincided with an increase in stress tolerance in plants (Ren et al., 2005). Stomata openings also not always occurred with a rising sensitivity to drought and water loss rates. For example, in Arabidopsis, the percentage of open stomata is much less in the WT plants than the LLA23 overexpression gene under stress, while transgenic plants have a declined rate of water loss and exhibit increased drought (Yang et al., 2005). In this work, there is meaningful difference in growth and development between the independent transgenic lines and the controls under severe drought stress. It has been demonstrated that lower stomata density and size do not mean biomass accumulation and lower CO2 assimilation (Yoo et al., 2009). For example, alteration in stomata development did not affect $\mathrm{CO} 2$ assimilation and biomass accumulation (Yoo et al., 2009). stomata density and pore aperture operate stomatal conductance (Hetherington \& Woodward, 2003; Nilson \& Assmann, 2007). It is shown that the average stomata density in the GsZFP1 overexpression lines was similar to that found in WT plants. For most C3 plants, the net $\mathrm{CO} 2$ assimilation rate saturates as stomatal conductance enhances as a result of non-stomata limitations, such as the regeneration of ribulose 1,5-bisphosphate (Zeiger \& Field, 1982). Therefore, a difference in stomata development cannot have a coincidental effect on $\mathrm{CO} 2$ 
280

281

282

283

284

285

286

287

288

289

290

291

292

293

294

295

296

297

298

299

300

301

302

303

304

305

306

307

308

309

assimilation. Overexpression of PtXERICO as a focal point in woody perennials improved drought tolerance by upregulation of endogenous ABA level ( Kim et al., 2020).

At the cellular level, membranes are thought to be the site of primary physiological injury (Blum 1988) and an early event in plant response to abiotic stress. Our results showed that under drought, the degree of membrane injury of wild type plants was more than transgenic plants.

Besides, the GpZF could regulate many biological processes to deal with drought, including proline and soluble sugar synthesis. It is proven that the accumulation of soluble sugars is considerably correlated to the drought tolerance in plants (Hoekstra, 2001), and usually, the measurement of proline content is relatively dependent on the sugar levels (Larher et al., 1993).

Sun et al., revealed that suffering plant from salt stress, ZFP179 might increase the expression of stress defence genes such as OsP5CS and follow by the accumulation of free proline, soluble sugars (Sun et al., 2010).

At this work, transgenic grass pea accumulated higher levels of proline and soluble sugars that function as osmolytes than the WT plants under drought stress conditions. Maintaining a high RWC occurred as a result of the increased soluble sugar and proline levels. In comparison with WT plants, the transgenic plants illustrated high RWC content.

\section{Acknowledgments}

The work was supported and funded by the ACECR and the Research Institute of Applied Science. In addition, the authors thank the Research Institute of Forests and Rangeland and the agricultural organization of Golestan province for providing the grass pea seeds.

\section{Conflict of interest}

The authors declare no conflict of interest.

\section{Author contributions}

Mitra Parsa designed the project and analyzed and interpreted the data; Mona kashanchi and Amineh Zeinali performed the experiments; Elaheh Pourfakhraei helped analyze the data and write the paper. 
bioRxiv preprint doi: https://doi.org/10.1101/2021.10.19.464954; this version posted October 19, 2021. The copyright holder for this preprint (which was not certified by peer review) is the author/funder. All rights reserved. No reuse allowed without permission.

\section{Data availability}

311 All data supporting the findings of this study are available within the paper. 


\section{References}

Almeida, N. F., Krezdorn, N., Rotter, B., Winter, P., Rubiales, D., \& Vaz Patto, M. C. 2015. Lathyrus sativus transcriptome resistance response to Ascochyta lathyri investigated by deep Supersage analysis. Frontiers in plant science 6, 178.

Bajji, M., Kinet, J.-M., \& Lutts, S. 2002. The use of the electrolyte leakage method for assessing cell membrane stability as a water stress tolerance test in durum wheat. Plant growth regulation 36(1), 61-70.

Bates, L. S., Waldren, R. P., \& Teare, I. 1973. Rapid determination of free proline for water-stress studies. Plant and soil 39(1), 205-207.

Chen, L., Ren, F., Zhong, H., Jiang, W., \& Li, X. 2010. Identification and expression analysis of genes in response to high-salinity and drought stresses in Brassica napus. Acta Biochim Biophys Sin 42(2), 154-164.

Chrispeels, H. E., Oettinger, H., Janvier, N., \& Tague, B. W. 2000. AtZFP1, encoding Arabidopsis thaliana $\mathrm{C} 2 \mathrm{H} 2$ zinc-finger protein 1, is expressed downstream of photomorphogenic activation. Plant molecular biology 42(2), 279-290.

Ciftci-Yilmaz, S., \& Mittler, R. 2008. The zinc finger network of plants. Cellular and Molecular Life Sciences 65(7), 1150-1160.

Dixit, G. P., Parihar, A. K., Bohra, A., \& Singh, N. P. 2016. Achievements and prospects of grass pea (Lathyrus sativus L.) improvement for sustainable food production. The Crop Journal 4(5), 407416.

Dubois, M., Gilles, K. A., Hamilton, J. K., Rebers, P. t., \& Smith, F. 1956. Colorimetric method for determination of sugars and related substances. Analytical chemistry 28(3), 350-356.

Hall, T. M. T. 2005. Multiple modes of RNA recognition by zinc finger proteins. Current opinion in structural biology 15(3), 367-373.

Hetherington, A. M., \& Woodward, F. I. 2003. The role of stomata in sensing and driving environmental change. Nature 424(6951), 901-908.

Hoekstra, A. F., A. Golovina, E. \& Buitink. 2001 J. Mechanisms of plant desiccation tolerance. Trends Plant Sci 6, 431-438.

Hu, Y., Li, W. C., Xu, Y., Li, G., Liao, Y., \& Fu, F.-L. 2009. Differential expression of candidate genes for lignin biosynthesis under drought stress in maize leaves. Journal of applied genetics 50(3), 213-223. 
Jiang, J., Su, M., Chen, Y., Gao, N., Jiao, C., Sun, Z., Wang, C. 2013. Correlation of drought resistance in grass pea (Lathyrus sativus) with reactive oxygen species scavenging and osmotic adjustment. Biologia 68(2), 231-240.

Kiełbowicz-Matuk, A. 2012. Involvement of plant C2H2-type zinc finger transcription factors in stress responses. Plant Science 185, 78-85.

Kim, M.-H., Cho, J.-S., Park, E.-J., Lee, H., Choi, Y.-I., Bae, E.-K., Ko, J.-H. 2020. Overexpression of a Poplar RING-H2 Zinc Finger, Ptxerico, Confers Enhanced Drought Tolerance via Reduced Water Loss and Ion Leakage in Populus. International journal of molecular sciences 21(24), 9454.

Kim, Y.-H., Kim, M. D., Park, S.-C., Yang, K.-S., Jeong, J. C., Lee, H.-S., \& Kwak, S.-S. 2011. SCOF-1-expressing transgenic sweetpotato plants show enhanced tolerance to low-temperature stress. Plant Physiology and Biochemistry 49(12), 1436-1441.

Kubo, K.-i., Sakamoto, A., Kobayashi, A., Rybka, Z., Kanno, Y., Nakagawa, H., Takatsuji, H. (1998). Cys2/His2 zinc-finger protein family of petunia: evolution and general mechanism of target-sequence recognition. Nucleic acids research 26(2), 608-615.

Lan Thi Hoang, X., Du Nhi, N. H., Binh Anh Thu, N., Phuong Thao, N., \& Phan Tran, L.-S. 2017. Transcription factors and their roles in signal transduction in plants under abiotic stresses. Current genomics 18(6), 483-497.

Larher, F., Leport, L., Petrivalsky, M., \& Chappart, M. 1993. Effectors for the osmoinduced proline response in higher plants. Plant physiology and biochemistry (Paris), 31(6), 911-922.

Lippuner, V., Cyert, M. S., \& Gasser, C. S. 1996. Two classes of plant cDNA clones differentially complement yeast calcineurin mutants and increase salt tolerance of wild-type yeast. Journal of Biological Chemistry 271(22), 12859-12866.

Livak, K. J., \& Schmittgen, T. D. 2001. Analysis of relative gene expression data using real-time quantitative PCR and the $2^{-\Delta \Delta \mathrm{CT}}$ method. methods 25(4), 402-408.

Luo, J., Song, Z., Yu, S., Cui, D., Wang, B., Ding, F., Li, N. 2014. Efficient generation of myostatin (MSTN) biallelic mutations in cattle using zinc finger nucleases. PloS one 9(4).

Luo, X., Cui, N., Zhu, Y., Cao, L., Zhai, H., Cai, H., Li, Y. 2012. Over-expression of GsZFP1, an ABA-responsive $\mathrm{C} 2 \mathrm{H} 2$-type zinc finger protein lacking a QALGGH motif, reduces ABA sensitivity and decreases stomata size. Journal of plant physiology 169(12), 1192-1202.

Molnár, G., Bancoş, S., Nagy, F., \& Szekeres, M. 2002. Characterisation of BRH1, a brassinosteroidresponsive RING-H2 gene from Arabidopsis thaliana. Planta 215(1), 127-133.

Mukoko Bopopi, J., Vandeputte, O. M., Himanen, K., Mol, A., Vaessen, Q., El Jaziri, M., \& Baucher, M. 2010. Ectopic expression of PtaRHE1, encoding a poplar RING-H2 protein with E3 
ligase activity, alters plant development and induces defence-related responses. Journal of experimental botany 61(1), 297-310.

Ni, F.-T., Chu, L.-Y., Shao, H.-B., \& Liu, Z.-H. 2009. Gene expression and regulation of higher plants under soil water stress. Current genomics 10(4), 269-280.

Nilson, S. E., \& Assmann, S. M. 2007. The control of transpiration. Insights from Arabidopsis. Plant Physiology 143(1), 19-27.

Ren, Z.-H., Gao, J.-P., Li, L.-G., Cai, X.-L., Huang, W., Chao, D.-Y., Lin, H.-X. 2005. A rice quantitative trait locus for salt tolerance encodes a sodium transporter. Nature genetics $37(10)$, 1141-1146.

Sakai, H., Medrano, L. J., \& Meyerowitz, E. M. 1995. Role of SUPERMAN in maintaining Arabidopsis floral whorl boundaries. Nature 378(6553), 199-203.

Sun, S.-J., Guo, S.-Q., Yang, X., Bao, Y.-M., Tang, H.-J., Sun, H., Zhang, H.-S. 2010. Functional analysis of a novel Cys2/His2-type zinc finger protein involved in salt tolerance in rice. Journal of experimental botany 61(10), 2807-2818.

Takatsuji, H. 1998. Zinc-finger transcription factors in plants. Cellular and Molecular Life Sciences CMLS, 54(6), 582-596.

Tian, Z. D., Zhang, Y., Liu, J., \& Xie, C. H. 2010. Novel potato C2H2-type zinc finger protein gene, StZFP1, which responds to biotic and abiotic stress, plays a role in salt tolerance. Plant biology 12(5), 689-697.

Urga, K., Fufa, H., Biratu, E., \& Husain, A. 2005. Evaluation of Lathyrus sativus cultivated in Ethiopia for proximate composition, minerals, $\beta$-ODAP and anti-nutritional components. African Journal of Food, Agriculture, Nutrition and Development 5(1).

van der Krol, A. R., van Poecke, R. M., Vorst, O. F., Voogd, C., van Leeuwen, W., Borst-Vrensen, T. W., . . . van der Plas, L. H. 1999. Developmental and wound-, cold-, desiccation-, ultravioletB-stress-induced modulations in the expression of the petunia zinc finger transcription factor gene ZPT2-2. Plant Physiology 121(4), 1153-1162.

Varshney, R. K., Hiremath, P. J., Lekha, P., Kashiwagi, J., Balaji, J., Deokar, A. A., Gaur, P. M. 2009. A comprehensive resource of drought-and salinity-responsive ESTs for gene discovery and marker development in chickpea (Cicer arietinum L.). BMC genomics 10(1), 1-18.

Wang, K. 2006. Agrobacterium protocols (Vol. 1): Springer.

Wang, X. L., Zhong, Y., \& Cheng, Z. M. 2014. Evolution and expression analysis of the CCCH zinc finger gene family in Vitis vinifera. The Plant Genome 7(3), plantgenome 2014.2005.0019. 
Yang, C.-Y., Chen, Y.-C., Jauh, G. Y., \& Wang, C.-S. 2005. A lily ASR protein involves abscisic acid signaling and confers drought and salt resistance in Arabidopsis. Plant Physiology 139(2), 836846.

Yang, T., Jiang, J., Burlyaeva, M., Hu, J., Coyne, C. J., Kumar, S., Chang, J. 2014. Large-scale microsatellite development in grasspea (Lathyrus sativus L.), an orphan legume of the arid areas. BMC plant biology 14(1), 1-12.

Yin, M., Wang, Y., Zhang, L., Li, J., Quan, W., Yang, L., Chan, Z. 2017. The Arabidopsis Cys2/His2 zinc finger transcription factor ZAT18 is a positive regulator of plant tolerance to drought stress. Journal of experimental botany 68(11), 2991-3005.

Yoo, C. Y., Pence, H. E., Hasegawa, P. M., \& Mickelbart, M. V. 2009. Regulation of transpiration to improve crop water use. Critical Reviews in Plant Science 28(6), 410-431.

Zeiger, E., \& Field, C. 1982. Photocontrol of the functional coupling between photosynthesis and stomatal conductance in the intact leaf: blue light and PAR-dependent photosystems in guard cells. Plant Physiology 70(2), 370-375.

Zhang, H., Liu, Y., Wen, F., Yao, D., Wang, L., Guo, J., Jiang, M. 2014. A novel rice C2H2-type zinc finger protein, ZFP36, is a key player involved in abscisic acid-induced antioxidant defence and oxidative stress tolerance in rice. Journal of experimental botany 65(20), 5795-5809.

Zhang, Y., Lan, H., Shao, Q., Wang, R., Chen, H., Tang, H., Huang, J. 2016. An A20/AN1-type zinc finger protein modulates gibberellins and abscisic acid contents and increases sensitivity to abiotic stress in rice (Oryza sativa). Journal of experimental botany 67(1), 315-326. 


\section{Tables}

313 Table 1 gene-specific primers used for quantitative real-time PCR

\section{$314 \quad$ Figures}

315 Fig. 1 Bioinformatic analysis of GpZFp. A Multiple sequence alignment of amino acid 316 sequences of GpZF using ClustalW. B The phylogenetic tree of plant stress-responsive C2H2317 type ZFPs. C The position of $\mathrm{C} 2 \mathrm{H} 2 \mathrm{zf}$ in sequence.

318 Fig. 2 A. Map of the pbI-GpZF plasmid. The GpZF gene was under the control of the CaMV 35S

319 promoter. B and C. Analysis of GpZF transcript level in transgenic grass pea and WT plants by 320 qRT-PCR and real-time RT-PCR. WT: non-transgenic plants, and 2, 11 and 22: independent 321 transgenic lines. B. Real-time PCR analysis of GpZF expression in the presence and in the 322 absence of drought (50\% and $25 \%$ field capacity); values indicate means of three biological 323 replicates. Significant differences indicate by Student's t-test and $\mathrm{P}<0.05$.

324 Fig. 3 Regeneration of adventitious shoot buds and plants from axillary meristem explants of 325 transgenic grass pea. A Callus induction from axillary explant B and C Somatic Embryogenesis 326 D Elongation of shoot.

327 Fig. 4 Drought stress tolerance of GpZF in transgenic grass pea. A Shoot height of plants under 328 control conditions and drought treatments. B. Dry weight of plants in the presence and in the 329 absence of drought. C. Survival rate under drought stress

330 Fig. 5 Drought stress tolerance in wild-type and transgenic grass pea A. Relative water content, 331 B. Relative membrane permeability, C. Free proline, D. Soluble sugar content. 
bioRxiv preprint doi: https://doi.org/10.1101/2021.10.19.464954; this version posted October 19, 2021. The copyright holder for this preprint (which was not certified by peer review) is the author/funder. All rights reserved. No reuse allowed without permission.

1

Table 1 gene-specific primers used for quantitative real-time PCR

3

4

5

6

7

8 
bioRxiv preprint doi: https://doi.org/10.1101/2021.10.19.464954; this version posted October 19, 2021. The copyright holder for this preprint (which was not certified by peer review) is the author/funder. All rights reserved. No reuse allowed without permission.

A

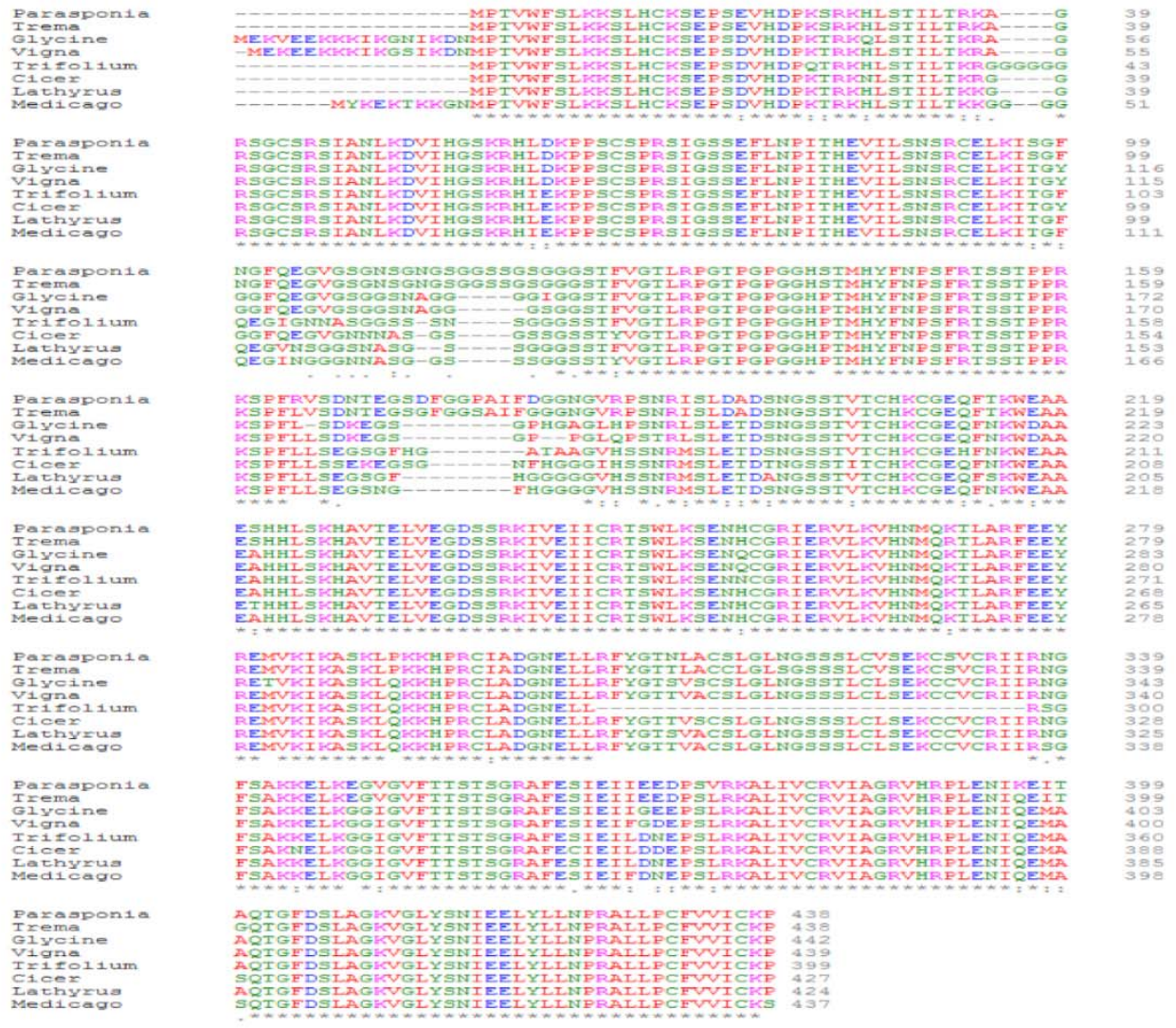

B

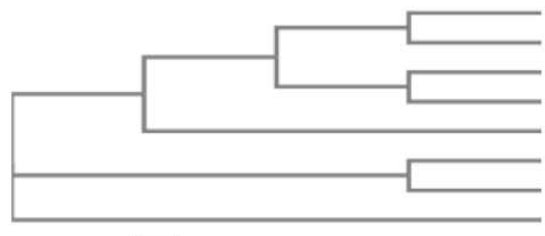

$\overleftarrow{0.01}$
Parasponia 0.01337

Trema 0.01174

Glycine 0.02032

Vigna 0.01393

Cicer 0.04061

Trifolium 0.03724

- Lathyrus 0.01888

Medicago 0.02261

C
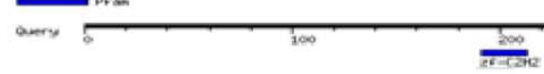

\begin{tabular}{|c|c|c|c|}
\hline Pfam & $\begin{array}{c}\text { Position } \\
\text { (Independent E-value) }\end{array}$ & Description & Alignment Query \\
\hline$\underline{\mathbf{z f}-}$ & $191 \ldots . .213(0.17)$ & PF00096, Zinc finger, & TCHKCGEQFSKWEAAETHHLSkH \\
$\mathrm{C} 2 \mathrm{H} 2$ & & $\mathrm{C} 2 \mathrm{H} 2$ type & kCpdCgkSFkrksnLkrHirt.H \\
\hline
\end{tabular}

Fig. 1 Bioinformatic analysis of GpZFp. A Multiple sequence alignment of amino acid sequences of GpZF using 12 ClustalW. B The phylogenetic tree of plant stress-responsive C2H2-type ZFPs. C The position of C2H2 $\mathrm{zf}$ in sequence. 
A

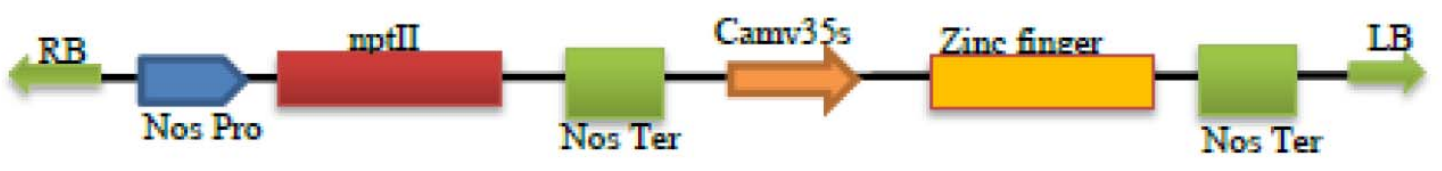

B

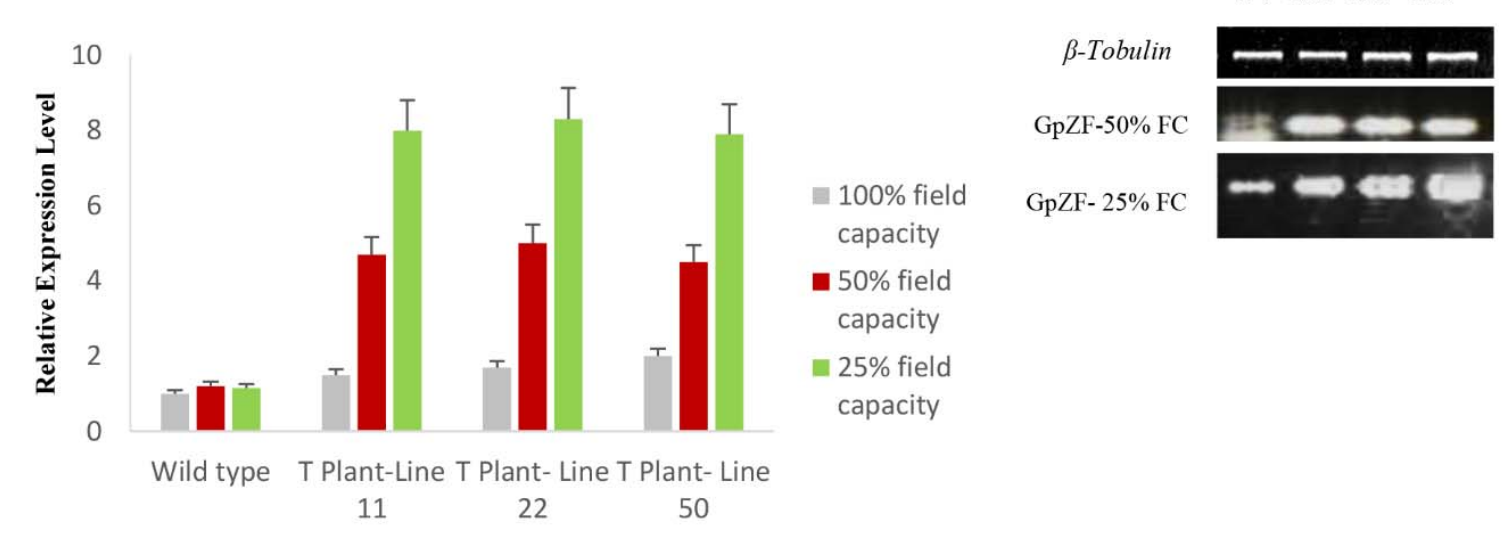

Fig. 2. A. Map of the pbI-GpZF plasmid. The GpZF gene was under the control of the CaMV 35S promoter. B and C. Analysis of GpZF transcript level in transgenic grass pea and WT plants by qRT-PCR and real-time RT-PCR. WT: non-transgenic plants, and 2, 11 and 22: independent transgenic lines. B. Real-time PCR analysis of GpZF expression in the presence and in the absence of drought (50\% and 25\% field capacity); values indicate means of three biological replicates. Significant differences indicate by Student's t-test and $\mathrm{P}<0.05$. 

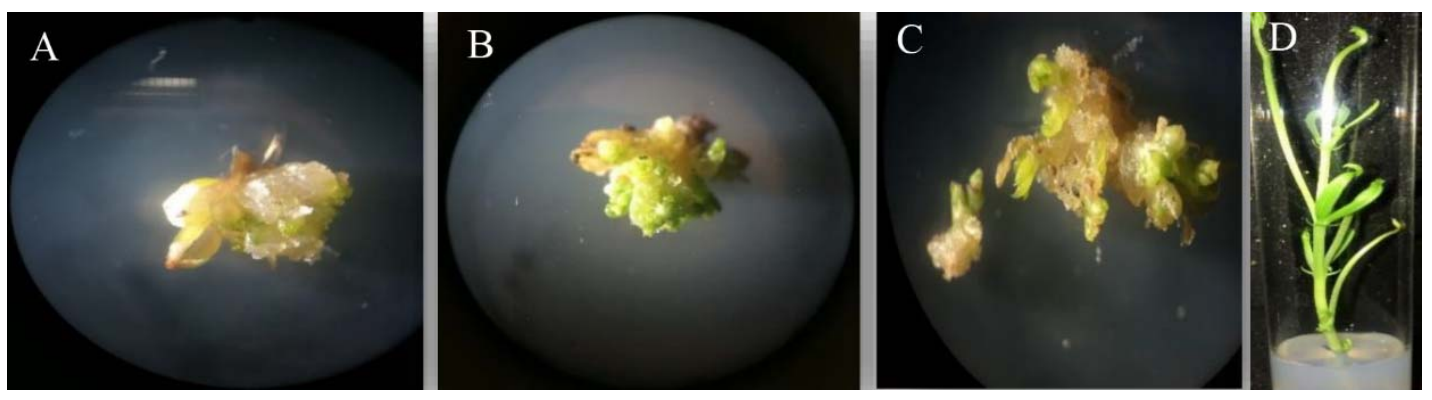

22

23 Fig. 3 Regeneration of adventitious shoot buds and plants from axillary meristem explants of transgenic grass pea. A Callus induction from axillary explant B and C Somatic embryogenesis D Elongation of shoot. 

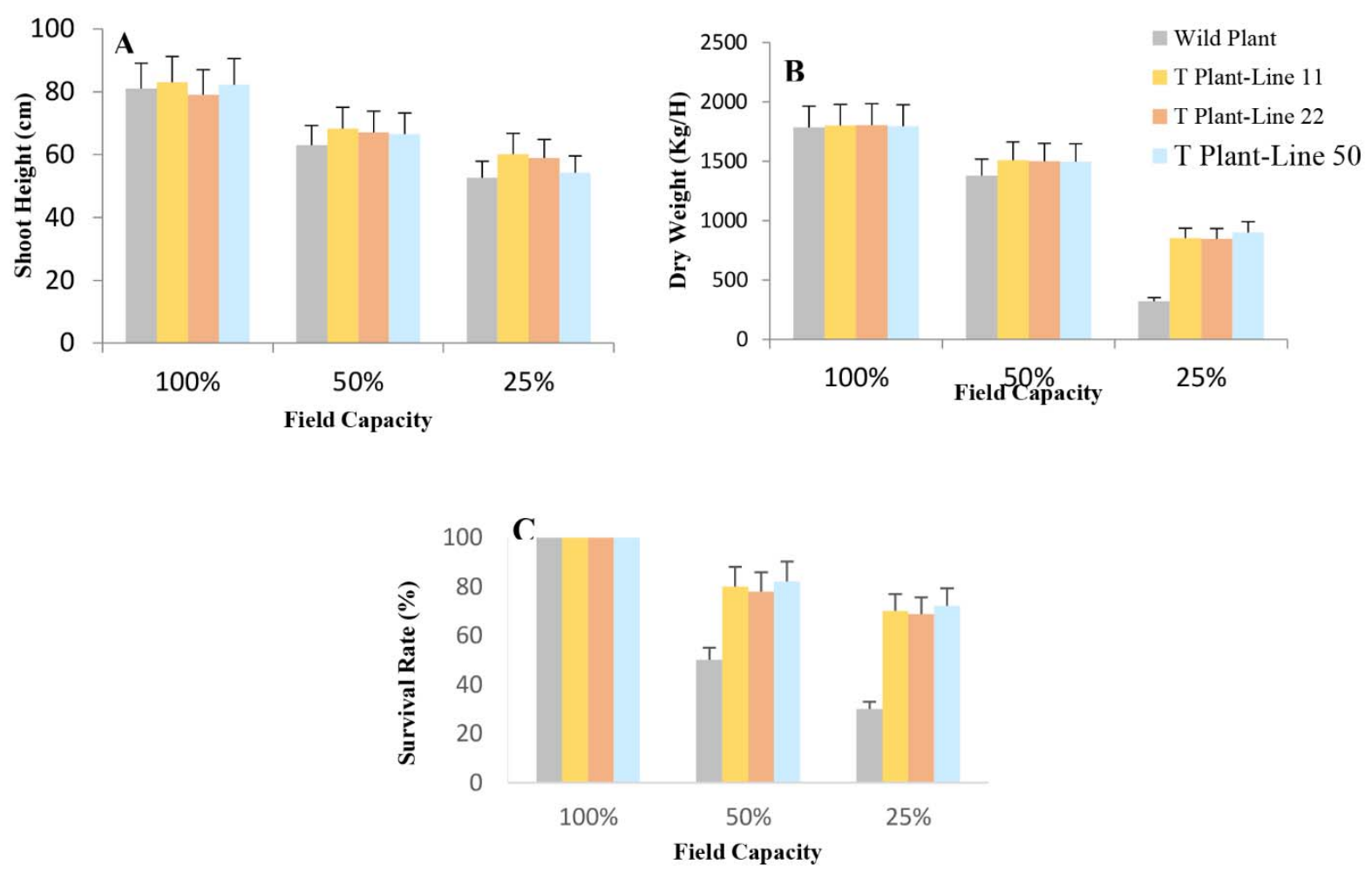

28

Fig. 4. Drought stress tolerance of GpZF in transgenic grass pea. A Shoot height of plants under control conditions and drought treatments. B. Dry weight of plants in the presence and in the absence of drought. C. Survival rate under drought stress 

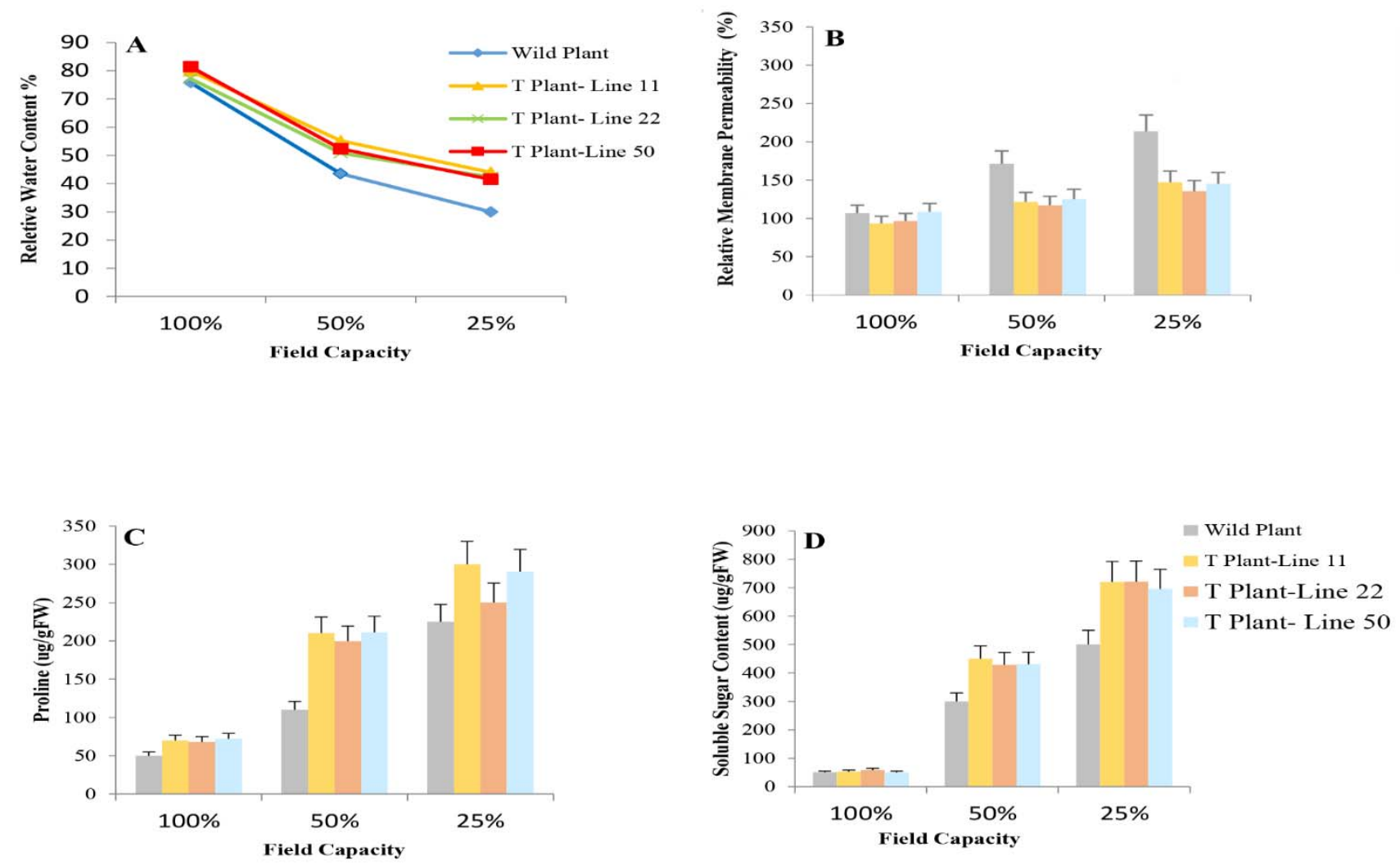

33 Fig. 5. Drought stress tolerance in wild-type and transgenic grass pea A. Relative water content, B. Relative membrane permeability, C. Free proline, D. Soluble sugar content. 
RSGCSRSIANI KDVIHGSRRHIDRP S SCSPRSIGSSEFINPITHEVIISWSRCEIRISGF RSGCSRSIANI FDVIHGSRRHIDRP SCSPRSIGSSEFINPIIHEVI SNSRCEIRISGF RSGCSRSI ANL KDVI HGSRRHI DRP PSCSPRSIGSSEFINPI I HEVII SW SRCEIRI IGY

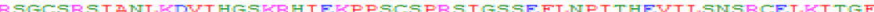
RST SRST AWT TDUTHCSERHI RSGCSRSTATI KDVIHGSTRHIEKPFSCSPRSIGSSEFINPITHENII SNSRCEIVITGF RSGCSRSIANI KDVIHGSRRHIERPF SCSPRSIGSSEFINPITHEVII SNSRCEIRIIGF

NGFOEGVGSGNSGNGSGGSSGSGGGSTFVGTIRFGIPGFGGHSTMHYFNFSFRTSSTPFR NTF

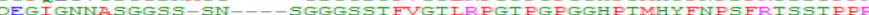

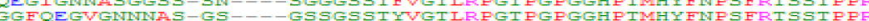
QEGVISGGSNA SGUSU--SGGGSST FVGTLRFGIPGPGGHPTMHYFNPSFRT SSTPFR REGINGGGNNASG-GS-_-_SSGGSSTYVGILRPGIPGPGGHPTMHYFNPSFRISSIPAR

FSP FRVS DNTEGSDFGGPAIFDGGNGVRP SNRI SI DADSNGSSTVICHRCGEQFIRTEAA

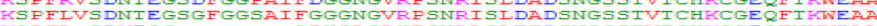

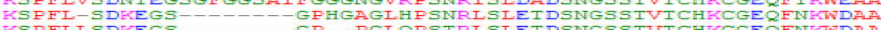

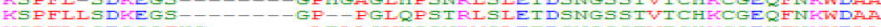

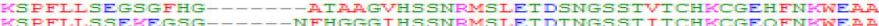
RSPFI. SSEREGSG----D-NFHGGGIHSSNRMSIETDTNGSSTITCHRCGEQFNRWEAR

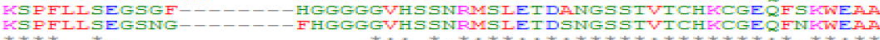

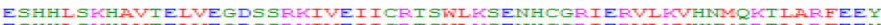
ESHHI SRHAVIEIVEGDSSRIIVEI I CRI SWL RSENHCGRIERVI RVHMMQRTIARFEEY

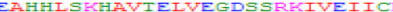
EAHHI SRHAVIEIVEGDSSREIVEI I CR I SWLKSENNCGR I ERVI FVHNMOKT IARFEEY EAHHLSRHA IELVEGDSSRRIVEI I CRISWLKSENHCGR IERVI RVHMMORI IARFEEY EAHHISKHAVIEIVEGDSSRKIVEIICRISWIKSENHCGRIERVIRVHNMQRTIMRFEEY

REMVKI KASKI PKKHPRCIADGNELIRFYGTNLACSLGINGSSSICVSEKCSVCRIIRNG REMVKI KAS SKI PKKKHPRCIADGNEIIRFYGTIIACCLGISGSSSICVSEKCSVCRI IRNG REIVKI KA SKI QKKKHPRCIA DGNEI IREYGISVSCSL GINGS S I C L SEKCCVCRIIRNG REMVKI KASKI QKKH PRCIADGNEILRFYGI IVACSLGINGSSSICISEKCCVCRI IRNG REMVKI KASKI QKKHPRCIADGNEII-_-

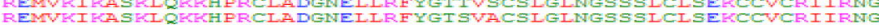

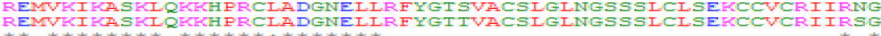

FSARKEIREGVGVFIISISGRAFESIEI IEEDPSVRKAI IVCRVIRGRVHRPIENI REI I

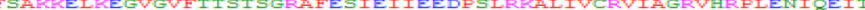
FSARK LKGGIGVIISISGRAFESIEIIUEEPSLRKAIIVCRVIAGRVHR LENIQEMA

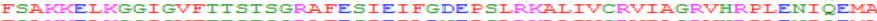

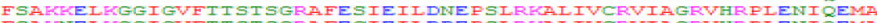
EARALINEI ESARKEI KGGIGVFIISISGRA ESIEI FDNEPSIRKAI IVCRVIAGRVHRPIENI REMA

\section{ARIGFDSIRGEVGIYSWIEEIYIINPRAIIPCFVVICKP 438} GQIGFDSIAGKVGI YSNIEEIYILNPRAII PCFVVICKR RQIGFDSIRGKVGIYSNIEEIYILNPRAII PCFVICKF ARIGFDSIAGKVGI YSNIEEIYILNPRAIIPCFVUICKF ARIGFDSIAGKVGIYSNIEEIYILNPRAIIPCFV ICKP AQIGEDSIAGKVGIYSNIEEIYILNPRAIIPCFNVICK KP 424

B

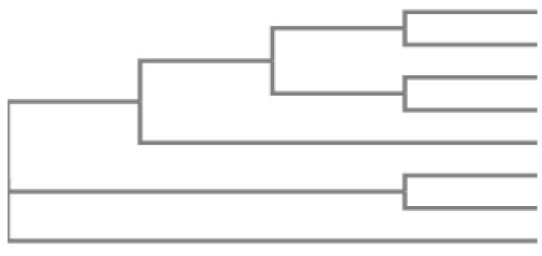

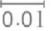

Parasponia 0.01337

Trema 0.01174

Glycine 0.02032

Vigna 0.01393

Cicer 0.04061

Trifolium 0.03724

- Lathyrus 0.01888

Medicago 0.02261

C

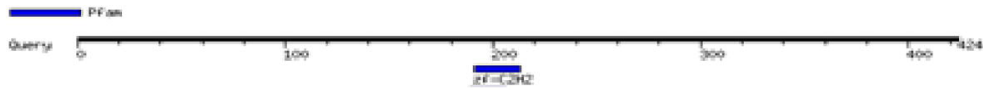

\begin{tabular}{|c|c|c|c|}
\hline Pfam & $\begin{array}{c}\text { Position } \\
\text { (Independent E-value) }\end{array}$ & Description & Alignment Query \\
\hline$\underline{\mathrm{zf}-}$ & $191 \ldots . .213(0.17)$ & PF00096, Zinc finger, & TCHKCGEQFSKWEAAETHHLSkH \\
$\underline{\mathrm{C} 2 \mathrm{H} 2}$ & & C2H2 type & kCpdCgksFkrksnLkrHirt.H \\
\hline
\end{tabular}




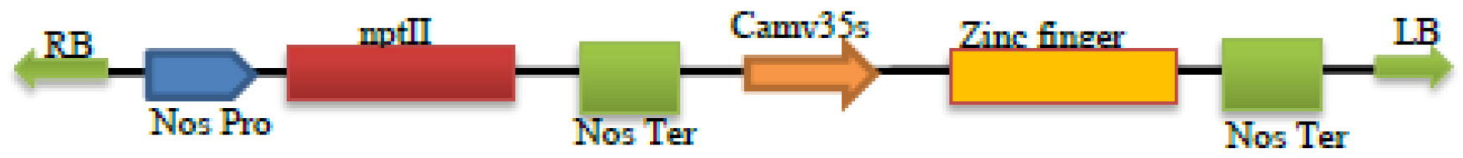

B

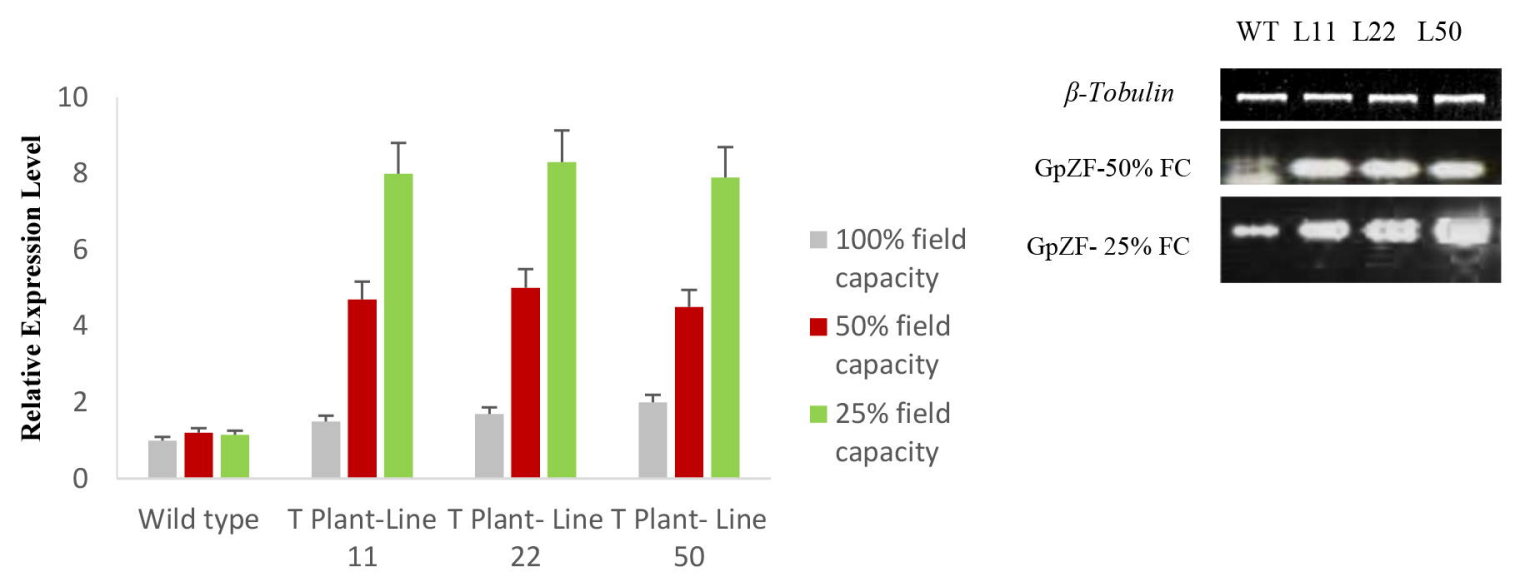



82 

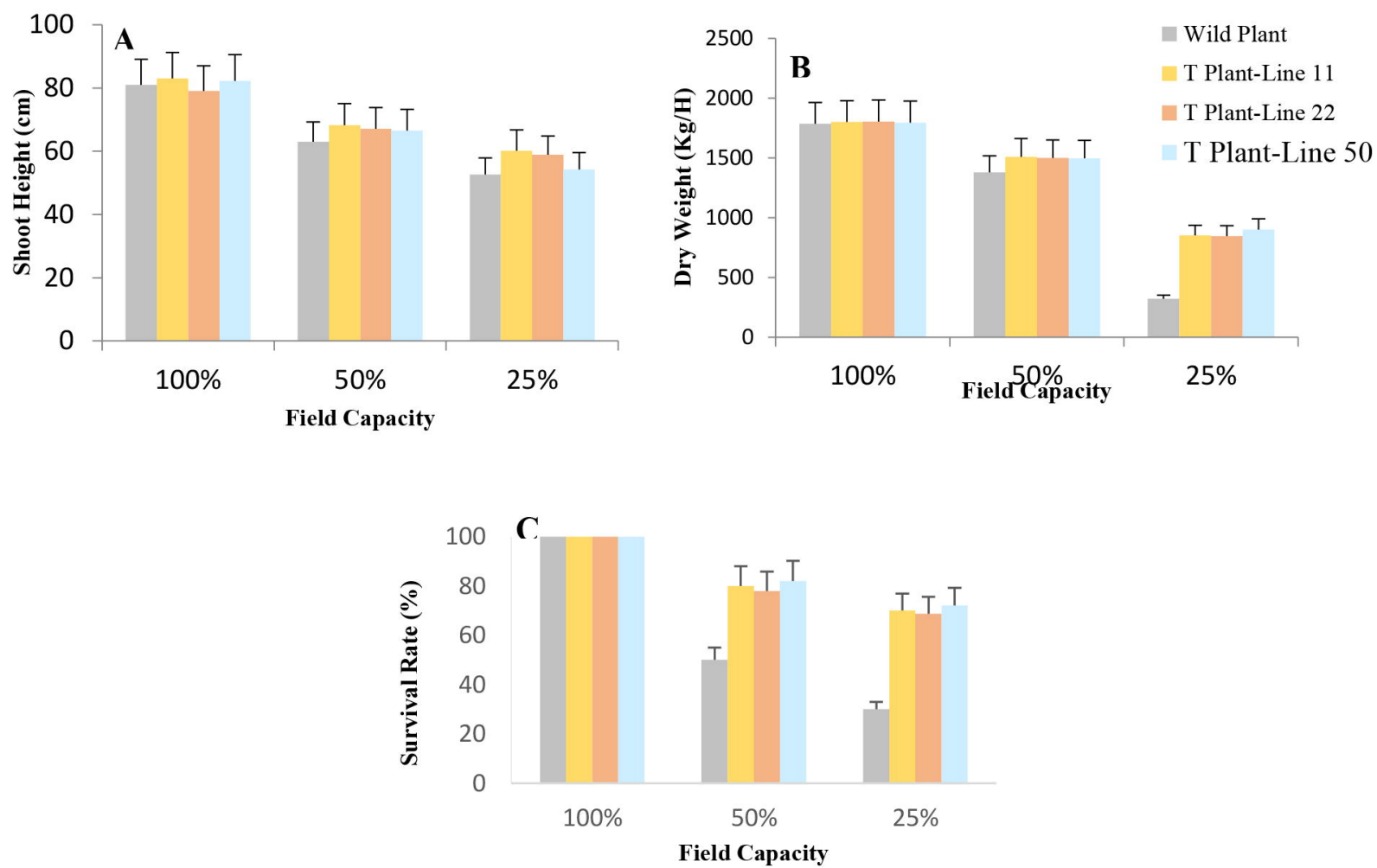

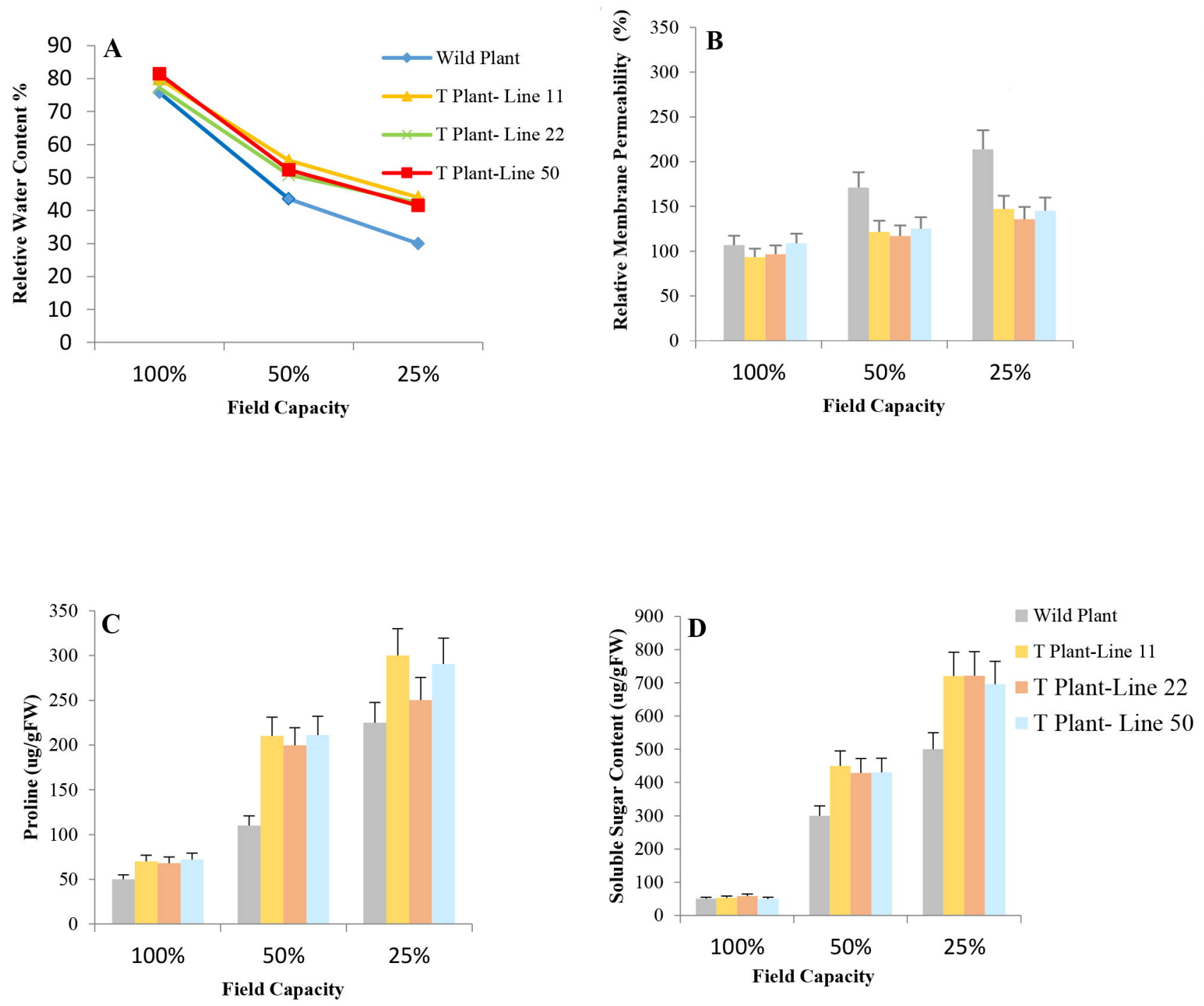